\title{
Utmost response time of long-wave HgCdTe photodetectors operating under zero voltage condition
}

\author{
P. Martyniuk ${ }^{1}$ P. Madejczyk ${ }^{1} \cdot$ M. Kopytko ${ }^{1} \cdot$ W. Gawron ${ }^{1} \cdot$ \\ J. Rutkowski ${ }^{1}$
}

Received: 30 August 2017/Accepted: 9 December 2017/Published online: 19 December 2017

(C) The Author(s) 2017. This article is an open access publication

\begin{abstract}
The paper reports on the long-wave infrared $\mathrm{HgCdTe}$ detector for utmost short response time operating for unbiased and room temperature condition. The response time was calculated at the level of $\sim 220-520$ ps for zero bias condition. It was shown that depending on architecture extra series resistance $\leq 20 \Omega$ related to the processing allows to reach response time within the range $\sim 220 \mathrm{ps}$. The highest detectivity of the simulated structure was assessed at the level of $\sim 10^{8}$ Jones assuming immersion.
\end{abstract}

Keywords LWIR $\cdot \mathrm{HgCdTe} \cdot$ Response time

\section{Introduction}

Applications requiring frequencies $>1 \mathrm{GHz}$ and operating under zero voltage and room temperatures contribute to the development of the new device architectures (Piotrowski and Rogalski 2007; Rogalski 2011; Wojtas et al. 2012). That trend is also visible in the long-wave (8-12 $\mu \mathrm{m}, \mathrm{LWIR})$ range $\mathrm{HgCdTe}$ detectors. Reaching the utmost response time $\left(\tau_{s}\right)$, the detectivity $\left(D^{*}\right)$ will be reduced without any prospect of the background limited photodetection (BLIP) condition. According to experimental data the LWIR $\mathrm{N}^{+} \mathrm{pP}^{+} \mathrm{n}^{+}$ based photodetectors with doping and composition gradient layers at particular heterojunction reach response time in several nanoseconds range while designed for non-

This article is part of the Topical Collection on Numerical Simulation of Optoelectronic Devices, NUSOD' 17.

Guest edited by Matthias Auf der Maur, Weida Hu, Slawomir Sujecki, Yuh-Renn Wu, Niels Gregersen, Paolo Bardella.

P. Martyniuk

piotr.martyniuk@wat.edu.pl

1 Institute of Applied Physics, Military University of Technology, 2 Kaliskiego Str., 00-908 Warsaw, Poland 
equilibrium condition and operating under zero voltage and room temperature. Figure 1 presents measured response time for the LWIR multilayer $\mathrm{N}^{+} \mathrm{pP}^{+} \mathrm{n}^{+}$detector with proper interfaces at heterojunctions versus voltage with nominal active layer composition, $x_{C d}=0.196$ and doping $N_{A}=5 \times 10^{16} \mathrm{~cm}^{-3}$ confirming that for zero voltage, $\tau_{s}$ stays within the range 5-10 ns for operating temperature, $T \sim 200-300 \mathrm{~K}$. If presented detector is highly biased, response time was assessed at the level of $200 \mathrm{ps}(V=-700 \mathrm{mV})$ for all analyzed temperatures. Within the range 200-230 K response time saturates for voltages $V>-300 \mathrm{mV}$ while the highest $\tau_{s}$ is reached for biases within the range $(50-100 \mathrm{mV})$. For room temperature operation, the highest response time is reached for $V=-250 \mathrm{mV}$. The higher temperature the peak value of the response time moves to higher reverse voltages. At the same time, assuming that detector is immersed, those devices exhibit $D^{*} \sim 10^{9}$ Jones (Madejczyk et al. 2013; Pawluczyk et al. 2015; Madejczyk et al. 2017).

\section{Simulation procedure and results}

Our approach to maximize response time in comparison with the three-layer $\mathrm{N}^{+} \mathrm{pP}^{+}$ structure invented and introduced by Elliot et al. for non-equilibrium conditions is lowering of the $\mathrm{P}^{+}$barrier layer by composition gradient within $\mathrm{p}^{+}-\mathrm{n}^{+}$transition layer (gradientcontact layers) (Ashley and Elliott 1985; Irvine 1992; Elliot et al. 1996). $\mathrm{P}^{+}$barrier composition, $x_{C d}$ was reduced to the LWIR absorber's level, i.e. 0.19 . $\mathrm{P}^{+}$barrier composition directly influences detector's dark current deteriorating detectivity. The nominal $\mathrm{HgCdTe}$ multilayer graded gap structure with doping and composition gradients at particular heterojunctions is presented in Fig. 2. The highly doped $N_{A}=10^{17} \mathrm{~cm}^{-3}$ active layer with thickness $d=1 \mu \mathrm{m}$ was implemented to reach ultrafast detector. Device architecture was changed by composition gradient of the $\mathrm{p}^{+}-\mathrm{n}^{+}$transition layer within the range $x_{C d}=0.1-0.19$. Low frequency resistance was calculated to be at the level of $\sim 1.5 \Omega$ for all analyzed structures. Detector structure was simulated with software APSYS by Crosslight Inc. (2016). The photocurrent's time dependence was simulated based on Li and Dutton model (1991). Theoretical simulations of the ultrafast HgCdTe heterostructures have been performed by numerical solving of Poisson's and the

Fig. 1 Measured response time of the LWIR multilayer $\mathrm{HgCdTe}$ $\mathrm{N}^{+} \mathrm{pP}^{+} \mathrm{n}^{+}$structure with proper interfaces at heterojunctions versus voltage (nominal active layer $x_{C d}=0.196$ and $N_{A}=5 \times 10^{16} \mathrm{~cm}^{-3}$ )

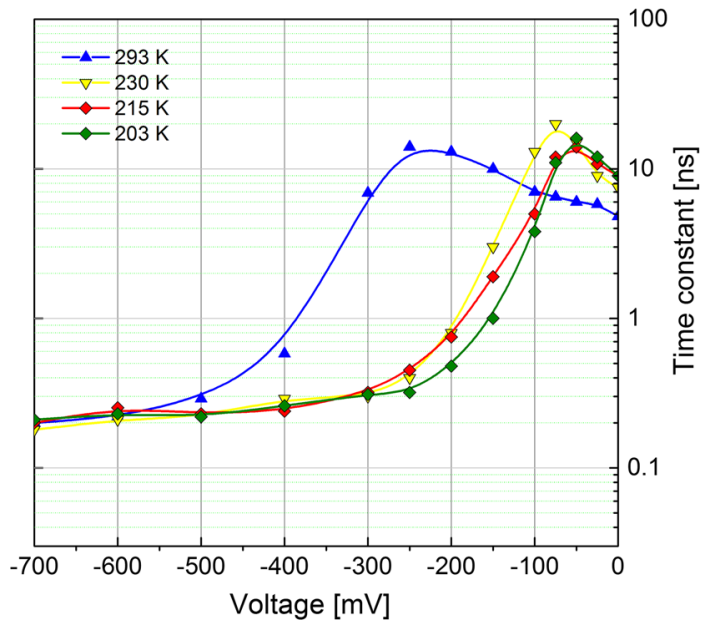




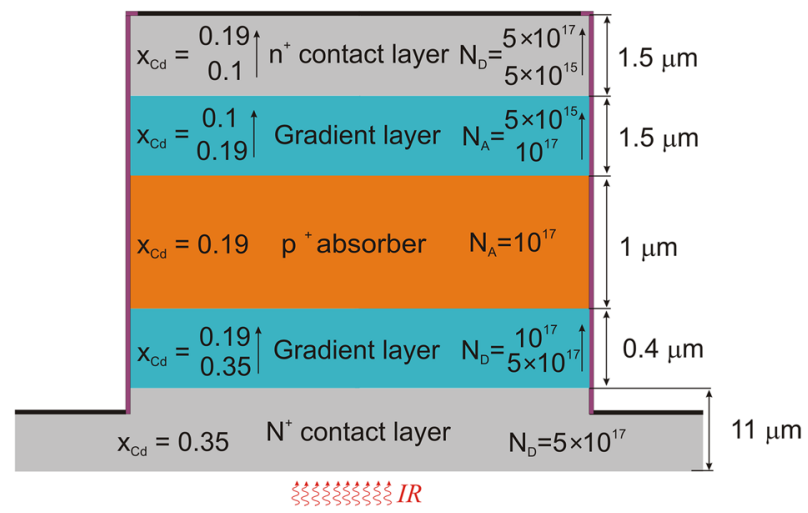

Fig. 2 LWIR $\mathrm{HgCdTe}$ structure exhibiting response time, $\tau_{s}<1 \mathrm{~ns}$ for unbiased condition and room temperature operation

electron/hole current continuity equations by the Newton-Richardson method. The equations describing the drift-diffusion model are presented in detail in the APSYS manual (2016). The used model assumes electrical and optical properties to include the influence of radiative, Auger, Shockley-Read-Hall (SRH) generation-recombination (GR) mechanisms at any mesh point within the device. Auger GR mechanism was simulated using Casselman and Petersen approximation of parabolic bands and non-degenerate statistics (Casselman and Petersen 1980). Energy bandgap was calculated by Hansen's paper et al. (1982). The zero bias electron mobility was taken from the formula based on Scott's paper, where the hole mobility was assumed as $1 \%$ of the electron mobility (Scott 1972). Intrinsic concentration's Cd composition $\left(x_{C d}\right)$ and temperature dependence was calculated using Hansen and Schmidt model (1983).

Since detector structure is intended to operate at zero bias condition the both band-toband (BTB) and trap-assisted (TAT) tunneling mechanisms were not included in simulations. An absorption was assumed in active layer region and absorption coefficient was estimated according to Kane model including its composition, doping and temperature dependences. Proper doping and composition grading were introduced to prevent form discontinuities in energy band profiles between contact-absorber $\left(\mathrm{N}^{+}-\mathrm{p}\right)$, absorber-barrier $\left(\mathrm{p}-\mathrm{P}^{+}\right)$and finally barrier-contact $\left(\mathrm{P}^{+}-\mathrm{n}^{+}\right)$heterojunctions. The detailed parameters taken in modelling of LWIR HgCdTe heterostructures are presented in Table 1.

Energy band diagrams for selected $\mathrm{p}^{+}-\mathrm{n}^{+}$transition layer composition within the range $x_{C d}=0.1-0.19$ were presented in Fig. 3a-d.

Corresponding electric field drop along the simulated LWIR HgCdTe structure for short response time and selected $\mathrm{p}^{+}-\mathrm{n}^{+}$transition layer composition, $x_{C d}=0.1-0.19$ was presented in Fig. 4.

Response time was derived from photocurrent dependence on time where time for $\sim 1 /$ e drop from photocurrent's maximum value was assessed. Simulated photocurrent versus time was presented in Fig. 5.

Since detector operates under zero bias, it was assumed that detectivity was limited by thermal Johnson-Nyquist noise and assessed according to the relation: 
Table 1 Parameters taken in modelling of LWIR utmost response time of $\mathrm{HgCdTe}$ heterostructures

\begin{tabular}{|c|c|c|c|c|c|}
\hline & $\begin{array}{l}\text { Contact } \\
\text { layer }\end{array}$ & $\begin{array}{l}\text { Gradient } \\
\text { layer }\end{array}$ & $\begin{array}{l}\text { Active } \\
\text { layer }\end{array}$ & Gradient layer & Contact layer \\
\hline Doping $N_{A} ; N_{D}\left(\mathrm{~cm}^{-3}\right)$ & $5 \times 10^{17}$ & $5 \rightarrow 1 \times 10^{17}$ & $10^{17}$ & $1 \rightarrow 0.05 \times 10^{17}$ & $0.05 \rightarrow 5 \times 10^{17}$ \\
\hline $\begin{array}{l}\text { Doping Gauss tail } d x \\
(\mu \mathrm{m})\end{array}$ & 0.05 & & & & \\
\hline Composition $x$ & 0.35 & $0.35 \rightarrow 0.19$ & 0.19 & $0.19 \rightarrow 0.1$ & $0.1 \rightarrow 0.19$ \\
\hline Geometry $d(\mu \mathrm{m})$ & 11 & 0.4 & 1 & 1.5 & 1.5 \\
\hline Electrical area $A\left(\mu \mathrm{m}^{2}\right)$ & $100 \times 100$ & & & & \\
\hline Overlap matrix $F_{1} F_{2}$ & 0.2 & & & & \\
\hline Trap energy level $E_{\text {Trap }}$ & $0.33 \times \mathrm{E}_{\mathrm{g}}$ & & & & \\
\hline $\begin{array}{l}\text { Trap concentration } N_{\text {Trap }} \\
\quad\left(\mathrm{cm}^{-3}\right)\end{array}$ & $10^{14}$ & & & & \\
\hline \multicolumn{6}{|l|}{$\mathrm{SRH}\left(\mathrm{cm}^{-2}\right)$} \\
\hline$\sigma_{\mathrm{n}}$ & $5 \times 10^{-15}$ & & & & \\
\hline$\sigma_{\mathrm{p}}$ & $5 \times 10^{-15}$ & & & & \\
\hline Incident power $\left(\mathrm{Wm}^{-2}\right)$ & 500 & & & & \\
\hline
\end{tabular}

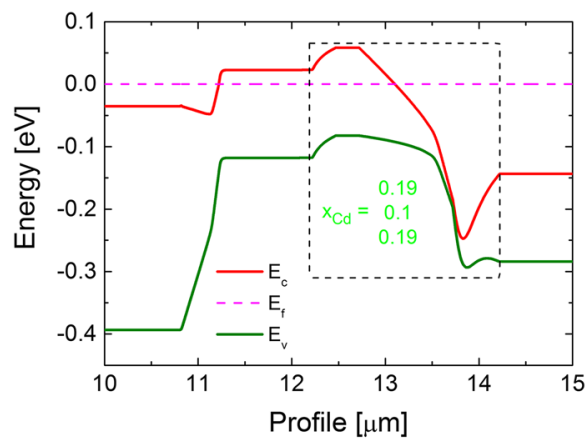

(a)

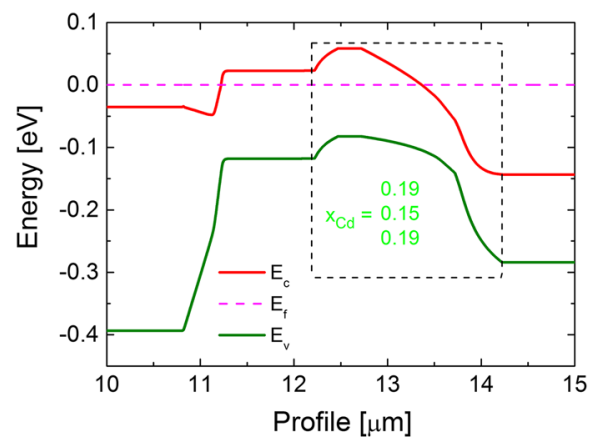

(c)

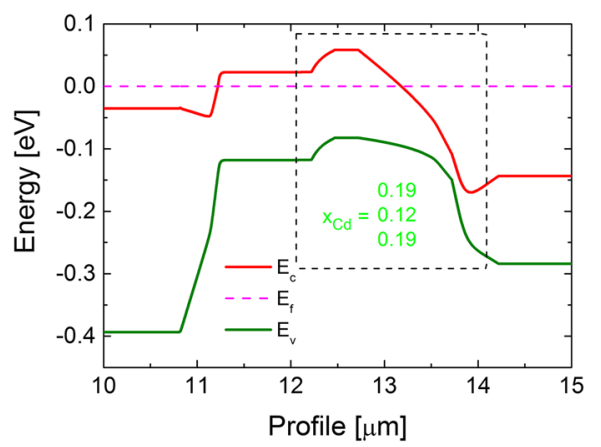

(b)

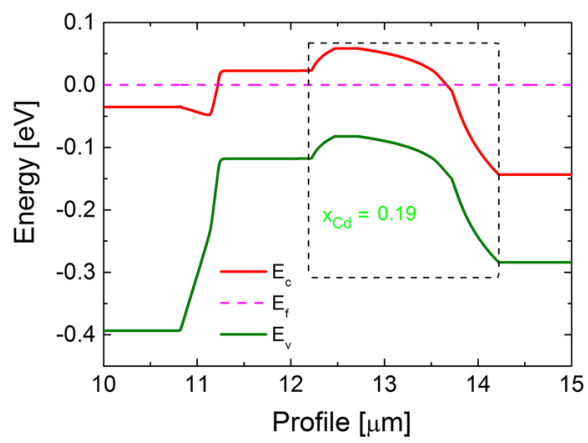

(d)

Fig. 3 Energy band diagram for LWIR HgCdTe structure for short response time for selected $\mathrm{p}^{+}-\mathrm{n}^{+}$ transition layer composition, $x_{C d}=0.1(\mathbf{a}) ; x_{C d}=0.12(\mathbf{b}) ; x_{C d}=0.15(\mathbf{c}) ; x_{C d}=0.19$ (d) 
Fig. 4 Electric field drop along LWIR HgCdTe structure for short response time and selected $\mathrm{p}^{+}-\mathrm{n}^{+}$transition composition, $x_{C d}=0.1-0.19$

Fig. 5 Normalized photocurrent versus time and selected $\mathrm{p}^{+}-\mathrm{n}^{+}$ transition layer composition, $x_{C d}=0.1-0.19$
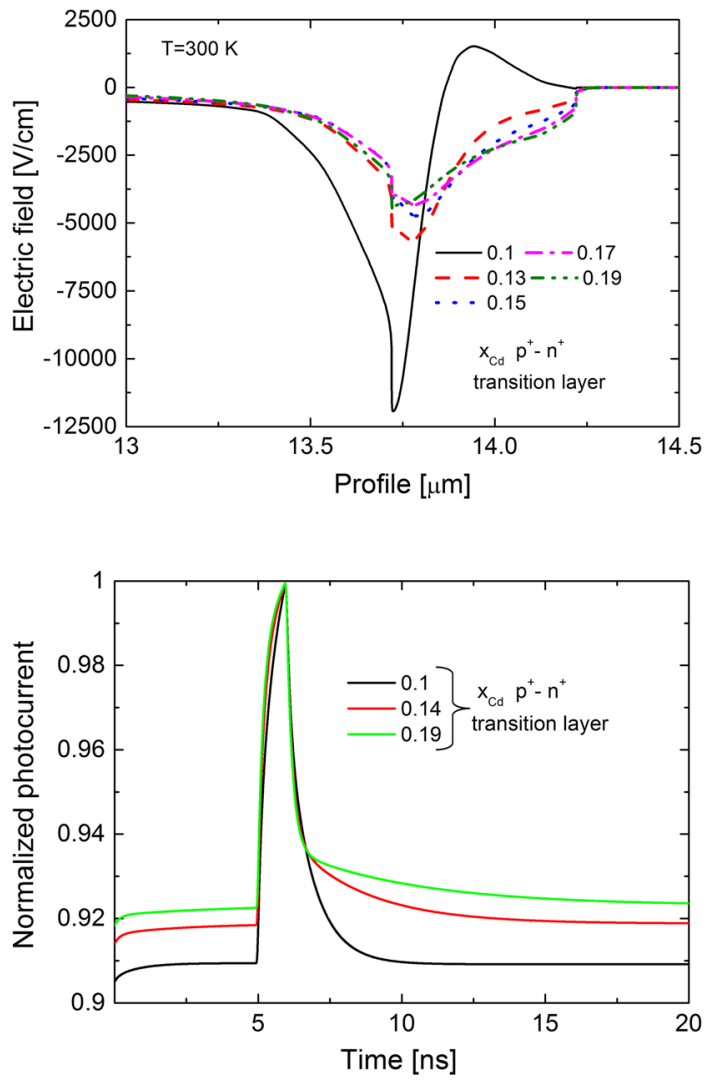

$$
D^{*}=\frac{n^{2} R_{i}}{\left(4 k_{B} T / R_{o} A\right)^{0.5}}
$$

where $R_{i}, k_{B}, R_{o}, A, n$ stands for current responsivity, Boltzmann constant, resistance at zero bias, detector's electrical area and GaAs substrate refractive index respectively. $D^{*}$ for

Fig. 6 Detectivity versus $\mathrm{p}^{+}-\mathrm{n}^{+}$ transition layer composition, $x_{C d}=0.1-0.19$

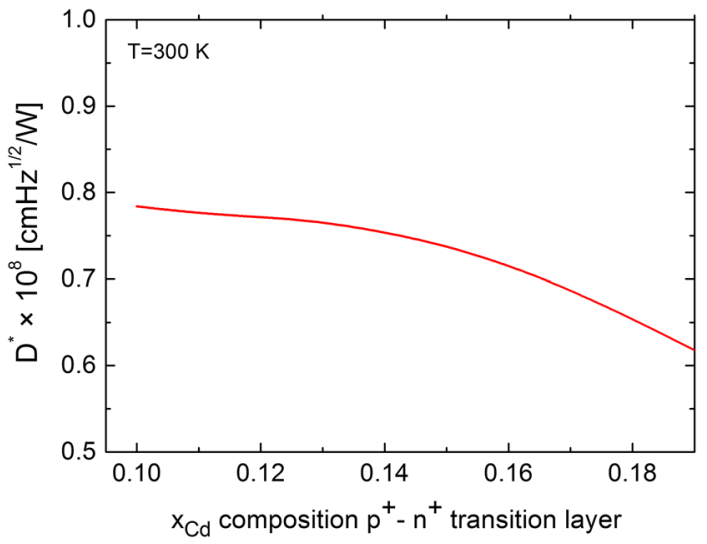


Fig. 7 Simulated response time of the LWIR HgCdTe structure for short response time versus $\mathrm{p}^{+}-\mathrm{n}^{+}$transition layer composition for selected extra series resistance,

$R_{\text {Series }}=0-20 \Omega$

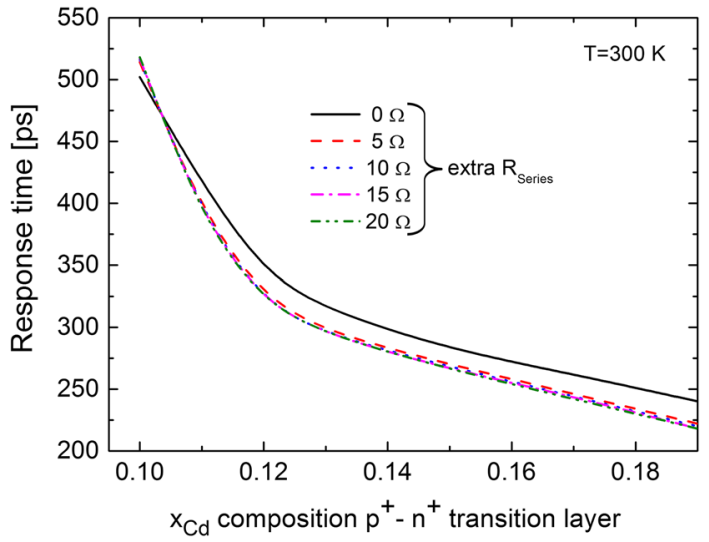

Fig. 8 Simulated response time of the LWIR HgCdTe structure for short response time versus extra series resistance for selected $\mathrm{p}^{+}-\mathrm{n}^{+}$transition layer compositions, $x_{C d}=0.1-0.19$

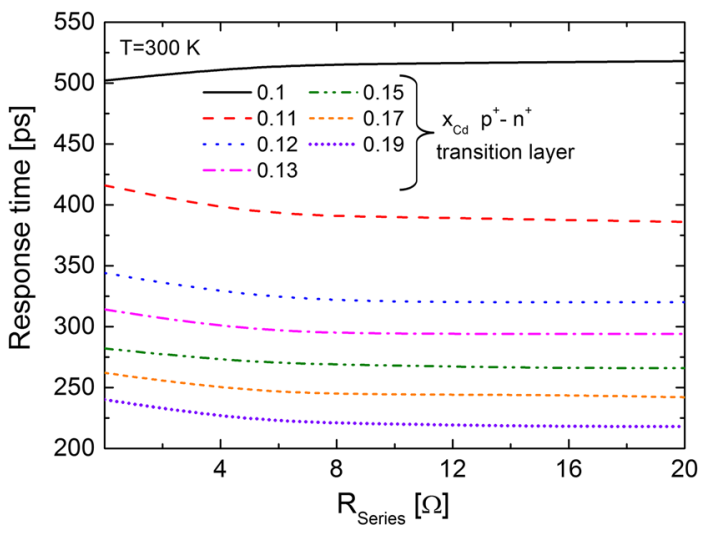

immersed detector was assessed at the level of $\sim 10^{8}$ Jones. Figure 6 presents $D^{*}$ dependence on $\mathrm{p}^{+}-\mathrm{n}^{+}$transition layer composition, $x_{C d}=0.1-0.19 . D^{*}$ increases nearly three times within analyzed $\mathrm{p}^{+}-\mathrm{n}^{+}$transition layer composition.

Figure 7 presents simulated response time versus $\mathrm{p}^{+}-\mathrm{n}^{+}$transition layer composition for selected extra series resistance $R_{\text {Series }}=0-20 \Omega$. The higher $\mathrm{p}^{+}-\mathrm{n}^{+}$transition layer composition the shorter response time could be reached $\tau_{s}=220 \mathrm{ps}$. Changing $x_{C d}$ of the $\mathrm{p}^{+}-$ $\mathrm{n}^{+}$transition layer the electric field decreases versus $x_{C d}$ saturating at the level of $\sim 5000 \mathrm{~V} / \mathrm{cm}$ (see also Fig. 3a-d). The diffusion component of the response time was estimated at the level of $\sim 152 \mathrm{ps}$ (active layer $N_{A}=10^{17} \mathrm{~cm}^{-3}$ and $d=1 \mu \mathrm{m}$, ambipolar diffusion coefficient, $\left.D_{a}=2.73 \times 10^{-3} \mathrm{~m}^{2} / \mathrm{s}\right)$.

For each extra $R_{\text {Series }}$ drastic drop of the $\tau_{s} \sim 500-325$ ps is observed within the range $x_{C d} \sim 0.1-0.12$. Response time exhibits two slope behavior where response time dependence on $x_{C d}$ of the $\mathrm{p}^{+}-\mathrm{n}^{+}$transition layer is nearly linear. That behavior is related to the detector resistance dependence on $\mathrm{p}^{+}-\mathrm{n}^{+}$transition layer $x_{C d}$ composition being correlated with electric field drop on that transition layer.

Only for $\mathrm{p}^{+}-\mathrm{n}^{+}$transition $x_{C d}=0.1$ the response time increases versus extra $R_{\text {Series }}$ within the range 500-520 ps $\left(R_{\text {Series }}=0-20 \Omega\right)$. For $\mathrm{p}^{+}-\mathrm{n}^{+}$transition $x_{C d}>0.1$ the extra series resistance lowers response time and for $R_{\text {Series }}>6 \Omega$ response time saturates for all analyzed $\mathrm{p}^{+}-\mathrm{n}^{+}$transition layer compositions what was presented in Fig. 8. Saturation 
region means that detector net resistance is dominated by detector internal resistance, $R_{D}$ $\left(R_{\text {Series }}>R_{D}\right)$. Below $R_{\text {Series }}<6 \Omega$, and $\mathrm{p}^{+}-\mathrm{n}^{+} x_{C d}=0.1$ detector resistance $R_{D}>R_{\text {Series }}$ meaning that response time depends on $R_{\text {Series }}$.

\section{Conclusions}

Theoretical utmost short response time $\tau_{s} \leq 520$ ps for LWIR HgCdTe structure exhibiting $D^{*} \sim 10^{8}$ Jones was presented. That level of detectivity was calculated assuming immersion. Improvement in response time could be achieved by increasing composition of $\mathrm{p}^{+}-\mathrm{n}^{+}$transition layer, however by optimization of the detector in terms of the response time detectivity deteriorates.

Acknowledgements This paper has been completed with the financial support of The National Centre for Research and Development-the Grant No. TANGO1/2665576/NCBR/2015.

Open Access This article is distributed under the terms of the Creative Commons Attribution 4.0 International License (http://creativecommons.org/licenses/by/4.0/), which permits unrestricted use, distribution, and reproduction in any medium, provided you give appropriate credit to the original author(s) and the source, provide a link to the Creative Commons license, and indicate if changes were made.

\section{References}

APSYS Macro/User's Manual ver. 2016. Crosslight Software, Inc. (2016)

Ashley, T., Elliott, C.T.: Non-equilibrium mode of operation for infrared detection. Electron. Lett. 21, 451-452 (1985)

Casselman, T.N., Petersen, P.E.: A comparison of the dominant Auger transitions in $p$-type (HgCd)Te. Solid State Commun. 33, 615-619 (1980)

Elliot, C.T., Gordon, N.T., Hall, R.S., Philips, T.J., White, A.M., Jones, C.L., Maxey, C.D., Metcalfe, N.E.: Recent results on MOVPE grown heterostructure devices. J. Electron. Mater. 25, 1139-1145 (1996)

Hansen, G.L., Schmidt, J.L.: Calculation of intrinsic carrier concentration in $\mathrm{Hg}_{1-\mathrm{x}} \mathrm{Cd}_{\mathrm{x}} \mathrm{Te}$. J. Appl. Phys. 54, $1639-1640$ (1983)

Hansen, G.L., Schmidt, J.L., Casselman, T.N.: Energy gap versus alloy composition and temperature in $\mathrm{Hg}_{1-\mathrm{x}} \mathrm{Cd}_{\mathrm{x}}$ Te. J. Appl. Phys. 53, 7099-7101 (1982)

Irvine, J.C.: Recent development in MOCVD of $\mathrm{Hg}_{1-x} \mathrm{Cd}_{x}$ Te. Proc. SPIE 1735, $92-99$ (1992)

Li, Q., Dutton, R.W.: Numerical small-signal AC modeling of deep-level-trap related frequency-dependent output conductance and capacitance for GaAs MESFET's on semi-insulating substrates. IEEE Trans. Electron Devices 38, 1285-1288 (1991)

Madejczyk, P., Gawron, W., Martyniuk, P., Kębłowski, A., Piotrowski, A., Pawluczyk, J., Pusz, W., Kowalewski, A., Piotrowski, J., Rogalski, A.: MOCVD grown HgCdTe device structure for ambient temperature LWIR detectors. Semicond. Sci. Technol. 28(10), 105017 (2013). https://doi.org/10.1088/ 0268-1242/28/10/105017

Madejczyk, P., Gawron, W., Martyniuk, P., Kębłowski, A., Pusz, W., Pawluczyk, J., Kopytko, M., Rutkowski, J., Rogalski, A., Piotrowski, J.: Engineering steps for optimizing high temperature LWIR HgCdTe photodiodes. Infrared Phys. Technol. 81, 276-281 (2017)

Pawluczyk, J., Piotrowski, J., Pusz, W., Koźniewski, A., Orman, Z., Gawron, W., Piotrowski, A.: Complex behavior of time response of HgCdTe HOT photodetectors. J. Electron. Mater. 44, 3163-3173 (2015)

Piotrowski, J., Rogalski, A.: High-Operating Temperature Infrared Photodetectors. SPIE Press, Bellingham (2007)

Rogalski, A.: Infrared Detectors. CRC Press, Boca Raton (2011)

Scott, W.: Electron mobility in $\mathrm{Hg}_{1-\mathrm{x}} \mathrm{Cd}_{\mathrm{x}} \mathrm{Te}$. J. Appl. Phys. 43, 1055 (1972)

Wojtas, J., Bielecki, Z., Stacewicz, T., Mikołajczyk, J., Nowakowski, M.: Ultrasensitive laser spectroscopy for breath analysis. Opto Electron. Rev. 20, 26-39 (2012) 